\title{
Association between cervicocephalic kinesthetic sensibility and frequency of subclinical neck pain
}

\author{
Hsin-Yi Lee ${ }^{\mathrm{a}}$, Jung-Der Wang ${ }^{\mathrm{a}, \mathrm{b}}$, Grace Yao ${ }^{\mathrm{c}}$, Shwu-Fen Wang ${ }^{\mathrm{d}, *}$ \\ anstitute of Occupational Medicine and Industrial Hygiene, College of Public Health, National Taiwan University, Taipei, Taiwan, ROC \\ ${ }^{\mathrm{b}}$ Department of Internal Medicine, National Taiwan University Hospital, Taipei, Taiwan, ROC \\ ${ }^{\mathrm{c}}$ Department and Graduate Institute of Psychology, College of Science, National Taiwan University, Taipei, Taiwan, ROC \\ ${ }^{\mathrm{d}}$ School and Graduate Institute of Physical Therapy, College of Medicine, National Taiwan University, Room 310, 3F., No. 17, Xu-Zhou Road, \\ Zhongzheng District, Taipei, Taiwan, ROC
}

Received 12 August 2006; received in revised form 12 March 2007; accepted 16 April 2007

\begin{abstract}
Although impaired neck proprioception has been demonstrated in patients with chronic neck pain, previous studies have not consistently shown any association between pain intensity and proprioceptive performance. We therefore investigated whether temporal aspects of pain are associated with cervicocephalic kinesthetic sensibility. One hundred and twenty-seven adults with or without subclinical neck pain undertook two tasks, repositioning their heads to the neutral head position (head-to-NHP) and target position (head-to-target) in sagittal and transverse plane. Absolute error was calculated from position data recorded by an ultrasound-based motion analysis system. Pain frequency, duration, and intensity were evaluated using a questionnaire. A mixed effects model was constructed to test the effect on reposition error by different pain factors, with age, gender and maximal cervical range of motion as covariates. A higher pain frequency was associated with greater reposition errors for all movement directions in the head-to-NHP task. No consistent effect was observed for pain intensity or duration. In the case of the head-to-target task, no consistent effect was observed for any of the three pain factors. The findings reveal that pain frequency, not the intensity or duration of pain, is associated with neck proprioception in individuals with subclinical neck pain.
\end{abstract}

(C) 2007 Elsevier Ltd. All rights reserved.

Keywords: Neck proprioception; Neck repositioning test; Pain frequency

\section{Introduction}

Neck pain is a major problem in modern society (National Institute of Occupational Safety and Health (NIOSH), 1997; Lee et al., 2005b), which frequently becomes chronic and/or recurring (Hoving et al., 2004). Sedentary office workers (such as bank employees) face a particularly high risk of developing neck pain, because when they work their neck and shoulders are generally static (Ariens et al., 2000, 2001). Subjects experiencing minor symptoms or subclinical neck pain have been

\footnotetext{
${ }^{*}$ Corresponding author. Tel.: + 886233228139 ; fax: +886233228161

E-mail address: sfwang@ntu.edu.tw (S.-F. Wang).
}

found to show changes in their neck's range of motion $(\mathrm{ROM})$, muscle endurance, and proprioception (Lee et al., 2005a). To prevent further progress, it is crucial to detect early signs of subclinical neck pain in order to allow prompt intervention.

Recently, increasing attention has been paid to the role that proprioception plays in neck pain (Sterling et al., 2003; Treleaven et al., 2005; Feipel et al., 2006). The cervicocephalic kinesthetic sensibility test (a frequently adapted method of determining neck proprioception) has been used to examine each subject's ability to return their head to a predetermined position without visual cues after they have moved (Revel et al., 1991; Loudon et al., 1997). The ability to do this has been reported to be impaired in patients with chronic neck 
pain (Revel et al., 1991; Heikkila and Astrom, 1996; Loudon et al., 1997; Feipel et al., 2006). Meanwhile, it has also been found that a proprioceptive training program (including head repositioning) can reduce the symptoms affecting the neck (Revel et al., 1994; Taimela et al., 2000). Since previous studies showed that proprioception is critical to the maintenance of joint stability under dynamic conditions (Ferrell et al., 1985), impairment of proprioception might be a predisposing factor in the development of clinical pain (Sharma et al., 1997; Vilensky, 2003; Panjabi, 2006).

Pain intensity has been a major focus for clinical research on neck pain (Revel et al., 1991; Heikkila and Astrom, 1996; Chiu et al., 2005). However, the subjective intensity of neck pain may not be easily quantified, especially if it occurs only intermittently, or is subclinical. As a result, previous studies have not consistently shown any association between pain intensity and cervicocephalic kinesthetic sensibility (Heikkila and Wenngren, 1998; Rix and Bagust, 2001; Armstrong et al., 2005). An alternative approach to the study of this type of subclinical neck pain is to quantify the temporal aspect of pain and examine if it is related to any change of neck proprioception. We therefore conducted this study, which evaluates repositioning errors, to determine whether the frequency, duration, and intensity of neck pain are associated with cervicocephalic kinesthetic sensibility.

\section{Methods}

\subsection{Participants}

Subjects were recruited via an invitation to participate, which was published in the newsletter produced by the National Federation of Bank's Employees Unions. One hundred and twenty-seven bank employees with or without neck pain (38 males and 89 females) volunteered for the study (Table 1). Exclusion criteria included the following: specific diagnosis of the cervical spine; traumatic spinal injury; vestibular impairment (demonstrated by vertigo, dizziness, or motor imbalance); diseases of rheumatological or endocrinological origin; progressive neurological disease; and pregnancy. Participants completed a questionnaire to provide basic demographic data, past medical history and pain characteristics. None had ever sought medical care or used traditional Chinese medicine to treat their symptoms of pain.

Ethical clearance for this study was provided by the local Institutional Human Study and Ethics Review Board. Each participant signed a consent form prior to participating in the experiment.

\subsection{Pain characteristics}

The measurement used for pain frequency was adapted from the symptoms questionnaire developed
Table 1

Characteristics of the study subjects $(N=127)$

\begin{tabular}{ll}
\hline Variable & \\
\hline Gender (\%) & 70.1 \\
Female & $41.8 \pm 8.5$ \\
Age (mean \pm standard deviation), year & \\
Pain frequency (\%) & 34.6 \\
Monthly & 34.6 \\
Weekly & 30.7 \\
Daily & \\
Pain duration of each episode (\%) & 32.3 \\
$<10$ min & 17.3 \\
$<1 \mathrm{~h}$ & 50.4 \\
$>1 \mathrm{~h}$ & \\
Pain intensity (\%) & 31.5 \\
Minimal & 55.1 \\
Mild & 13.4 \\
Moderate & \\
Cervical range of motion (mean \pm standard deviation), deg & $57.5 \pm 9.6$ \\
Flexion & $62.9 \pm 12.6$ \\
Extension & $66.8 \pm 9.6$ \\
Right rotation & $69.1 \pm 9.1$ \\
Left rotation &
\end{tabular}

by Westgaard et al. (1993), which was ranked according to one of the following categories: (1) "daily" (the pain has occurred every workday during the past two weeks); (2) "weekly" (the pain has occurred once or twice per week during the past two months; or (3) "monthly" (the pain occurs rarely, on a monthly basis). The average duration of each pain episode was recorded as: (1) less than $10 \mathrm{~min}$, (2) less than $1 \mathrm{~h}$, or (3) longer than $1 \mathrm{~h}$.

Information about the pain intensity was also recorded in terms of the subject's ability to carry out work while enduring the pain. For this, a five-level scale was used (Westgaard et al., 1993): (1) no pain; (2) only a slight feeling of discomfort during breaks; (3) slight, but noticeable pain during work and no interference with the performance of the task; (4) moderate pain during work and intermittent breaks needed to relieve the pain; (5) severe pain that interfered with work and was such that even breaks could not completely relieve it. The high test-retest reliability of these three pain questions was demonstrated in a pilot study of 18 subjects, in which the weighted kappa (Sim and Wright, 2005) ranged between 0.72 and 0.83 .

\subsection{Instrumentation}

An ultrasound-based coordinate measuring system (CMS 70P, Zebris Medizintechnik Gmbh, Tubingen, Germany) was used to assess cervical motion. This system includes two sets of triple markers on the head attachment and the shoulder cap, a transducer sensor stand for the sound wave, a computer system, and data- 
acquisition software (WinData v2.1). The triple marker set includes three ultrasound transmitters with frequencies of $35 \mathrm{kHz}$. The transducer sensor consisted of three microphones that recorded the ultrasound pulse with a sampling frequency of $25 \mathrm{~Hz}$. Cervical movement was processed automatically by the software, using the principle of coordinate transformation to determine the spatial coordinates of the triple markers on the head whose position changed in relation to a fixed set of triple markers on the shoulder (Dvir and Prushansky, 2000). The validity of measurement (Dvir and Prushansky, 2000; Malmstrom et al., 2003; Wang et al., 2005) and test-retest reliability (Mannion et al., 2000; Malmstrom et al., 2003; Wang et al., 2005) involved for assessing cervical ROM have been previously demonstrated.

\subsection{Testing procedure}

After explaining the test procedures to the subject, the investigator firmly fixed the head triple set of ultrasound transmitters on the subject's head with a Velcro strap. In order to determine neutral head position (NHP), the participants were asked to sit upright in a comfortable position and look straight ahead. The plane of the triple set of markers on the head was parallel to the sagittal plane of head movement. The shoulder triple set was attached to the right shoulder of the subject with a Velcro strap which also fastened the trunk to the chair back. The shoulder position was thus fixed, to ensure that the subject's shoulders could not move during the reposition test that followed. The investigator then calibrated the motion analysis system to an NHP.

The cervicocephalic kinesthetic sensibility test consisted of the following two tasks: Head-to-NHP and head-to-target. The head-to-NHP task required the subjects to close the eyes and then return to the predetermined upright head position after they had actively moved their head away from it (as described below). This task was similar to those used in the previous studies and has already been accepted as a reliable method (Revel et al., 1991; Heikkila and Astrom, 1996; Rix and Bagust, 2001). The head-totarget task was a modification of the technique used by Loudon et al. (1997). It tested an individual's ability to actively reposition their head at a target position, which is defined in this study as a self-selected mid-point within the subject's maximal ROM.

Subjects positioned their head in the baseline NHP. They were told to close their eyes throughout the subsequent tests. Firstly, subjects moved their head through the maximum ROM; this was recorded. After maximal ROM was reached, the subjects were asked to return to the NHP and move their head to a self-selected mid-point within the maximal ROM being tested; this was referred as the baseline target. Once the subjects had decided upon and remembered the baseline NHP and target, they performed three trials of the head-to-NHP task and two trials of the head-to-target task by returning to the predetermined baseline head position after active movement. Between each trial, the subjects' eyes remained closed and they were instructed to return to their actual NHP as precise as possible.

The repositioning tasks were performed through four directions of cervical motion (flexion/extension through the sagittal plane, and right/left rotation through the transverse plane) in a sequence with a 1-min interval between the directions; the sequence of motion plane was also randomized. During the test, subjects were instructed to move the heads slowly (at a rate of $10-15^{\circ} / \mathrm{s}$ ). The investigator remained blind to the subjects' responses on the pain questionnaire and used standardized commands. No verbal cues were given that would inform subjects about their actual performance. The whole procedure took less than 15 min for each subject. The test was a modified version of a method used previously in our laboratory, which had demonstrated an acceptable level of reproducibility (Lee et al., 2006).

\subsection{Data reduction and analysis}

When grading the five-level scale of pain intensity, five subjects reported "no pain", and two subjects reported "severe pain". To reduce the number of levels, we combined the 1st and 2nd categories to produce a "minimal intensity" category and the 4th and 5th categories to produce a "moderate intensity" category. The 3rd level in the original scale was re-classed as "mild intensity". The five subjects who reported no neck pain were grouped into the categories "monthly" for pain frequency and "less than $10 \mathrm{~min}$ " for pain duration.

For each movement direction, agreement between the predetermined angle, the neutral or target position, and the angle observed during the repositioning test was expressed by absolute errors (AEs), in terms of angular degree.

\subsection{Statistical analysis}

A linear mixed model was constructed to determine the effects of movement direction (flexion, extension, right/left rotation), repositioning task (head-to-NHP and head-to-target), and repeated trials on the repositioning errors. To match the trial numbers during the head-to-target task, we used the first two trials in the head-to-NHP task to represent the subjects' best performance. The potential confounding effects of gender and age were controlled by using these factors as the covariates in the model.

To investigate the association between head repositioning error and pain characteristics, which include the frequency, intensity and duration of pain, another mixed model was also developed. This model tests for 
differences of $\mathrm{AE}$ between groups with different pain level i.e. daily pain (or weekly pain) group against monthly pain group, moderate pain (or mild pain) group against minimal pain group and so on. Again age, and gender, as well as maximal cervical ROM were recruited as the covariates in the model. The random effect was assumed for measurements repeatedly performed on a subject. SPSS 11.0 for Windows (SPSS Inc., Chicago, IL) was used to perform all the statistical analyses. The significance level was set as $P<0.05$.

\section{Results}

\subsection{Demographics and pain characteristics}

Table 1 summarizes the demographic data and pain characteristics of 127 subjects recruited into the study. The mean age (and standard deviation) of the studied subjects was 41.8 (8.5) years. In all, $70 \%$ of subjects reported that the pain they experienced occurred less than daily. Over half of the study subjects $(50.4 \%)$ reported that their pain lasted longer than $1 \mathrm{~h}$ on average. About $87 \%$ of the subjects reported that the intensity of their pain was "minimal" or "mild". The subjects demonstrated acceptable neck flexibility for all ROMs except the ROM of extension, which was slightly less than the average value of $76.5^{\circ}$ reported for a sample of asymptomatic Taiwanese adults (Wang et al., 2005).

\subsection{Repositioning errors during the two tasks}

For all subjects, the reposition errors that resulted from each trial are summarized in Table 2. The analysis using the mixed model revealed that the $\mathrm{AE}$ that occurred in head-to-NHP task were significantly greater than those recorded in head-to-target task $(P<0.01)$. In the comparison of the directions of head movement, the $\mathrm{AE}$ of extension and flexion were significantly greater than those of rotations $(P<0.01)$. Because the subjects were not reoriented to actual NHP after each trial, a time-related increase of $\mathrm{AE}$ was also found regardless of task or movement direction. The repositioning error were significantly greater in the 2 nd trials than those in the 1st trials $(P<0.01)$.

\subsection{Relationship between pain characteristics and head repositioning errors}

A higher frequency of pain occurrence was significantly associated with greater AE in the head-to-NHP task after controlling the effect of age, gender, and cervical ROM (Table 3 ). In return from rotation, mean $\mathrm{AE}$ of the group with weekly pain (right rotation: $7.2 \pm 5.3^{\circ}$; left rotation: $8.3 \pm 6.5^{\circ}$ ) and daily pain (right rotation: $8.9 \pm 6.5^{\circ}$; left rotation: $9.1 \pm 8.1^{\circ}$ ) were
Table 2

Repositioning errors (mean \pm standard deviation) in terms of angular degree (deg) in serial head repositioning tests in subjects with subclinical neck pain

\begin{tabular}{llrll}
\hline Movement plane & Direction & \multicolumn{2}{l}{ No. of trial } \\
\cline { 3 - 5 } & & 1 st & 2nd & 3rd \\
\hline Head-to-neutral head position & & & \\
Sagittal plane & Flexed & $10.3 \pm 7.4$ & $11.8 \pm 7.4$ & $13.7 \pm 8.3$ \\
& Extended & $12.2 \pm 9.6$ & $15.5 \pm 10.8$ & $17.0 \pm 11.2$ \\
Transverse plane & Right rotated & $6.8 \pm 5.2$ & $7.3 \pm 5.8$ & $7.3 \pm 5.8$ \\
& Left rotated & $7.1 \pm 5.8$ & $8.0 \pm 7.7$ & $8.7 \pm 7.7$ \\
Head-to-target & & & & \\
Sagittal plane & Flexion & $5.3 \pm 4.3$ & $6.4 \pm 5.9$ & \\
& Extension & $4.2 \pm 3.8$ & $6.0 \pm 5.4$ & \\
Transverse plane & Right rotation & $4.3 \pm 3.6$ & $4.7 \pm 4.0$ & \\
& Left rotation & $4.0 \pm 3.7$ & $5.1 \pm 4.2$ & \\
\hline
\end{tabular}

significantly greater than $\mathrm{AE}$ of the group with monthly pain (right rotation: $5.7 \pm 4.4^{\circ}$; left rotation: $6.6 \pm 6.6^{\circ}$ ); (all $P<0.05$ ) Similar result was also found in return from flexion, even though the difference between daily pain group and monthly pain group did not reach statistical significance $(P=0.06)$. In return from extension, the significant difference was only found between daily pain $\left(17.9 \pm 12.5^{\circ}\right)$ and monthly pain group $\left(13.9 \pm 9.4^{\circ}\right) ;(P=0.002)$. At the same time, being older was significantly associated with increased $\mathrm{AE}$ in the head-to-NHP task $(P<0.01)$, except in the flexion direction. Being female was also significantly associated with increased $\mathrm{AE}$ in the head-to-target task $(P<0.05)$, except in the flexion direction. Neither pain intensity nor duration was found to have any consistent effect on repositioning errors.

\section{Discussion}

The present study revealed that individuals with higher pain frequency could not reproduce the NHP as accurately when repositioning their head. This finding supports the results of previous research (Revel et al., 1991; Heikkila and Astrom, 1996; Loudon et al., 1997; Feipel et al., 2006) and provides further evidence for a relationship between proprioceptive deficit and pain frequency. However, given the cross-sectional nature of our study, it cannot be determined whether the decrease observed in cervicocephalic kinesthetic sensibility is a cause or result of the increased pain frequency. We were not surprised to find that a significant result was only observed in the head-to-NHP task, since this task has been reported to be a more sensitive method of differentiating between subjects with and without neck pain than the task that involves subjects repositioning their head to a target position (Kristjansson et al., 2003). 
Table 3

Repositioning errors (mean \pm standard deviation) in terms of angular degree (deg) in head-to-neutral head position (NHP) and head-to-target task among subjects with monthly, weekly and daily neck pain

\begin{tabular}{|c|c|c|c|c|c|}
\hline Absolute error (deg) & $\begin{array}{l}\text { Monthly pain } \\
(n=44)\end{array}$ & $\begin{array}{l}\text { Weekly pain } \\
(n=44)\end{array}$ & $\begin{array}{l}\text { Daily pain } \\
(n=39)\end{array}$ & $\begin{array}{l}\text { Weekly pain vs. } \\
\text { monthly pain, } P \text { value }\end{array}$ & $\begin{array}{l}\text { Daily pain vs. } \\
\text { monthly pain, } P \text { value }\end{array}$ \\
\hline \multicolumn{6}{|l|}{ Head-to-NHP } \\
\hline Flexed & $10.1 \pm 6.6$ & $13.1 \pm 7.5$ & $12.7 \pm 9.2$ & 0.008 & 0.06 \\
\hline Extended & $13.9 \pm 9.4$ & $13.2 \pm 9.7$ & $17.9 \pm 12.5$ & 0.74 & 0.002 \\
\hline Right rotated & $5.7 \pm 4.4$ & $7.2 \pm 5.3$ & $8.9 \pm 6.5$ & 0.02 & 0.0001 \\
\hline Left rotated & $6.6 \pm 6.6$ & $8.3 \pm 6.5$ & $9.1 \pm 8.1$ & 0.004 & 0.004 \\
\hline \multicolumn{6}{|l|}{ Head-to-target } \\
\hline Flexion & $5.1 \pm 3.2$ & $6.5 \pm 5.8$ & $6.1 \pm 4.8$ & 0.07 & 0.23 \\
\hline Extension & $4.3 \pm 2.9$ & $5.7 \pm 4.7$ & $5.2 \pm 3.8$ & 0.08 & 0.67 \\
\hline Right rotation & $4.3 \pm 3.6$ & $4.8 \pm 3.9$ & $4.7 \pm 3.3$ & 0.57 & 0.77 \\
\hline Left rotation & $4.2 \pm 3.5$ & $4.3 \pm 2.7$ & $5.3 \pm 4.2$ & 0.28 & 0.01 \\
\hline
\end{tabular}

Mixed effect model was used to test the effect of pain frequency with age, gender and cervical range of motion as the covariates.

Two previous studies (Kristjansson et al., 2003; Treleaven et al., 2003) reported smaller repositioning errors in people with neck pain. In those studies, the authors used an electromagnetic measuring device to study the NHP repositioning error, and obtained a mean $\mathrm{AE}$ of $3.5^{\circ}$ in return from extension (Treleaven et al., 2003) and a mean $\mathrm{AE}$ of $2.8-4.5^{\circ}$ in return from rotation (Kristjansson et al., 2003; Kristjansson et al., 2003; Treleaven et al., 2003). Since both measuring devices (ultrasound-based system and electromagnetic system) had been demonstrated to have a good degree of reliability when used to measure cervical motion (Mannion et al., 2000; Jordan et al., 2000; Malmstrom et al., 2003; Wang et al., 2005), the different range of error between our study and the findings of Kristjansson et al. (2003) and Treleaven et al. (2003) might be explained by the different mathematical analysis in which the devices calculate the angular displacements in the given plane of movement. In the present study, the values of the repositioning errors in the head-to-NHP task were comparable to those obtained by a recent study undertaken by our laboratory which also used a Zebris device, and a similar approach, to assess head repositioning errors (Teng et al., 2007). The errors reported in the study of Teng et al. ranged from $10.7^{\circ}$ to $12.2^{\circ}$ in the sagittal plane and $9.1-10.3^{\circ}$ in the transverse plane. In addition, our data on cervical ROM was also comparable with the values that have been reported by previous studies (Wang et al., 2005; Lee et al., 2006), except that the range was small in the extension direction.

Although the usual repositioning tests cannot completely rule out the influence of the vestibular system (Guyton and Hall, 1996; Kandal et al., 2000), we tried to eliminate the vestibular system's effect by recruiting only subjects who showed no significant deficiency of the vestibular system. Moreover, the repositioning test was also performed at a low speed $\left(10-15^{\circ} / \mathrm{s}\right)$ to decrease vestibular stimuli (Guyton and Hall, 1996). We also controlled the effect of potential confounders (such as age, gender, and cervical ROM) by using them as covariates in the construction of the mixed model. Thus, it is unlikely that the above factors explain the observed association between pain frequency and repositioning errors.

Our finding that more frequent occurrences of pain were associated with greater repositioning errors (in the head-to-NHP task) seems to contradict those of Lee et al. (2005a), who found that an increased frequency of pain was associated with a decrease in repositioning errors. However, during the tests undertaken by Lee et al. (2005a) the subjects had their eyes open, which means that the participants might have been able to use visual cues to compensate when repositioning their heads. In contrast to pain frequency, no association between head repositioning accuracy and pain intensity was found in our study. This result was in accord with the previous studies of patients with chronic neck pain or whiplash injury (Revel et al., 1991; Heikkila and Wenngren, 1998; Rix and Bagust, 2001; Armstrong et al., 2005).

The finding that age was positively correlated with repositioning errors during the head-to-NHP task was consistent with the findings of studies of 18-66-year-old whiplash patients (Heikkila and Wenngren, 1998) and 45-65-year olds (Teng et al., 2007). Some investigators, however, have failed to detect this correlation when studying subjects under 55 years of age (Heikkila and Astrom 1996; Rix and Bagust, 2001). Age-related decline in proprioception has, however, also been observed in other weight-bearing joints, including the lower back (Parkhurst and Burnett, 1994), knee (Skinner et al., 1984), and ankle (Robbins et al., 1995).

It is possible that neck pain and proprioceptive deficiency may both sustain and perpetuate one another. Previous laboratory studies had provided compelling 
evidence that pain is capable of inducing changes in muscle spindle discharge (Mense and Skeppar, 1991; Johansson et al., 1993; Thunberg et al., 2002) and the proprioceptive properties of brainstem neurons (Capra and Ro, 2000). Disturbance of the proprioceptive system has been shown to interfere with motor control (Ferrell et al., 1985; Sainburg et al., 1993; Kavounoudias et al., 1999; Treleaven et al., 2005), and it has been suggested that aberrant motor control may expose the spinal components to abnormal and repetitive strain (O'Sullivan, 2005; Panjabi, 2006). Numerous authors have also reported an altered pattern of motor control in patients with neck pain (Nederhand et al., 2000; Falla et al., 2004; Jull et al., 2004; Szeto et al., 2005); however, its relationship with pain frequency has not yet been well investigated. Subsequent follow-up studies are needed to verify the hypothesized relationship between pain frequency, changes in motor control and neck proprioception in relation to the development of clinical neck pain.

\section{Conclusion}

The present study has provided further evidence that pain frequency, not the intensity or duration of pain, is associated with neck proprioception in individuals with subclinical neck pain. The examination of proprioception in repositioning to the neutral head position may be indicated for patients of increased frequency of neck pain.

\section{Acknowledgments}

The study was supported by the Institute of Occupational Safety and Health, Council of Labor Affairs, Taiwan (IOSH90-H331 and IOSH91-H122).

\section{References}

Ariens GA, Mechelen W, Bongers PM, Bouter LM. Physical risk factors for neck pain. Scandinavian Journal of Work, Environment \& Health 2000;26(1):7-19.

Ariens GA, Bongers PM, Douwes M, Miedema MC, Hoogendoorn WE, Bouter LM, et al. Are neck flexion, neck rotation, and sitting at work risk factors for neck pain? Results of a prospective cohort study. Occupational and Environmental Medicine 2001;58(3): 200-7.

Armstrong BS, McNair PJ, Williams M. Head and neck position sense in whiplash patients and healthy individuals and the effect of the cranio-cervical flexion action. Clinical Biomechanics 2005;20(7): $675-84$.

Capra NF, Ro JY. Experimental muscle pain produces central modulation of proprioceptive signals arising from jaw muscle spindles. Pain 2000;86(1-2):151-62.

Chiu TT, Lam TH, Hedley AJ. A randomized controlled trial on the efficacy of exercise for patients with chronic neck pain. Spine 2005; 30(1):E1-7.
Dvir Z, Prushansky T. Reproducibility and instrument validity of a new ultrasonography-based system for measuring cervical spine kinematics. Clinical Biomechanics 2000;15(9):658-64.

Falla D, Bilenkij G, Jull G. Patients with chronic neck pain demonstrate altered patterns of muscle activation during performance of a functional upper limb task. Spine 2004;29(13):1436-40.

Feipel V, Salvia P, Klein H, Rooze M. Head repositioning accuracy in patients with whiplash-associated disorders. Spine 2006;31(2): E51-8.

Ferrell WR, Baxendale RH, Carnachan C, Hart IK. The influence of joint afferent discharge on locomotion, proprioception and activity in conscious cats. Brain Research 1985;347(1):41-8.

Guyton AC, Hall JE. Textbook of medical physiology, 9th ed. Philadelphia: Saunders; 1996.

Heikkila H, Astrom PG. Cervicocephalic kinesthetic sensibility in patients with whiplash injury. Scandinavian Journal of Rehabilitation Medicine 1996;28(3):133-8.

Heikkila HV, Wenngren BI. Cervicocephalic kinesthetic sensibility, active range of cervical motion, and oculomotor function in patients with whiplash injury. Archives of Physical Medicine and Rehabilitation 1998;79(9):1089-94.

Hoving JL, Vet HC, Twisk JW, Deville WL, Koes BW, Bouter LM. Prognostic factors for neck pain in general practice. Pain 2004; 110(3):639-45.

Johansson H, Djupsjobacka M, Sjolander P. Influences on the gammamuscle spindle system from muscle afferents stimulated by $\mathrm{KCl}$ and lactic acid. Neuroscience Research 1993;16(1):49-57.

Jordan K, Dziedzic K, Jones PW, Ong BN, Dawes PT. The reliability of the three-dimensional FASTRAK measurement system in measuring cervical spine and shoulder range of motion in healthy subjects. Rheumatology 2000;39(4):382-8.

Jull G, Kristjansson E, Dall'Alba P. Impairment in the cervical flexors: a comparison of whiplash and insidious onset neck pain patients. Manual Therapy 2004;9(2):89-94.

Kandal ER, Schwartz JH, Jessell TM. Principles of neural science. 4th edn. New York: Mc-Graw Hill; 2000.

Kavounoudias A, Gilhodes JC, Roll R, Roll JP. From balance regulation to body orientation: two goals for muscle proprioceptive information processing? Experimental Brain Research 1999;124(1):80-8.

Kristjansson E, Dall'Alba P, Jull G. A study of five cervicocephalic relocation tests in three different subject groups. Clinical Rehabilitation 2003;17(7):768-74.

Lee H, Nicholson LL, Adams RD, Bae SS. Proprioception and rotation range sensitization associated with subclinical neck pain. Spine 2005a;30(3):E60-7.

Lee HY, Yeh WY, Chen CW, Wang JD. Prevalence and psychosocial risk factors of upper extremity musculoskeletal pain in industries of Taiwan: a nationwide study. Journal of Occupational Health 2005b;47(4):311-8.

Lee HY, Teng CC, Chai HM, Wang SF. Test-retest reliability of cervicocephalic kinesthetic sensibility in three cardinal planes. Manual Therapy 2006;11(1):61-8.

Loudon JK, Ruhl M, Field E. Ability to reproduce head position after whiplash injury. Spine 1997;22(8):865-8.

Malmstrom EM, Karlberg M, Melander A, Magnusson M. Zebris versus Myrin: a comparative study between a three-dimensional ultrasound movement analysis and an inclinometer/compass method: intradevice reliability, concurrent validity, intertester comparison, intratester reliability, and intraindividual variability. Spine 2003;28(21):E433-40.

Mannion AF, Klein GN, Dvorak J, Lanz C. Range of global motion of the cervical spine: intraindividual reliability and the influence of measurement device. European Spine Journal 2000;9(5):379-85.

Mense S, Skeppar P. Discharge behavior of feline gamma-motoneurones following induction of an artificial myositis. Pain 1991;46(2): 201-10. 
National Institute of Occupational Safety and Health (NIOSH). Musculoskeletal disorders and workplace factors: a critical review of epidemiologic evidence for work-related musculoskeletal disorders of the neck, upper extremity, and low back. Cincinnati: NIOSH, 1997.

Nederhand MJ, IJzerman MJ, Hermens HJ, Baten CT, Zilvold G. Cervical muscle dysfunction in the chronic whiplash associated disorder grade II (WAD-II). Spine 2000;25(15):1938-43.

O'Sullivan P. Diagnosis and classification of chronic low back pain disorders: maladaptive movement and motor control impairments as underlying mechanism. Manual Therapy 2005;10(4): 242-55.

Panjabi MM. A hypothesis of chronic back pain: ligament subfailure injuries lead to muscle control dysfunction. European Spine Journal 2006;15(5):668-76.

Parkhurst TM, Burnett CN. Injury and proprioception in the lower back. Journal of Orthopaedics and Sports Physical Therapy 1994; 19(5):282-95.

Revel M, Andre-Deshays C, Minguet M. Cervicocephalic kinesthetic sensibility in patients with cervical pain. Archives of Physical Medicine and Rehabilitation 1991;72(5):288-91.

Revel M, Minguet M, Gregoy P, Vaillant J, Manuel JL. Changes in cervicocephalic kinesthesia after a proprioceptive rehabilitation program in patients with neck pain: a randomized controlled study. Archives of Physical Medicine and Rehabilitation 1994;75(8): 895-9.

Rix GD, Bagust J. Cervicocephalic kinesthetic sensibility in patients with chronic, nontraumatic cervical spine pain. Archives of Physical Medicine and Rehabilitation 2001;82(7):911-9.

Robbins S, Waked E, McClaran J. Proprioception and stability: foot position awareness as a function of age and footwear. Age Ageing 1995;24(1):67-72.

Sainburg RL, Poizner H, Ghez C. Loss of proprioception produces deficits in interjoint coordination. Journal of Neurophysiology 1993;70(5):2136-47.

Sharma L, Pai YC, Holtkamp K, Rymer WZ. Is knee joint proprioception worse in the arthritic knee versus the unaffected knee in unilateral knee osteoarthritis? Arthritis and Rheumatism 1997;40(8):1518-25.
Sim J, Wright CC. The kappa statistic in reliability studies: use, interpretation, and sample size requirements. Physical Therapy 2005; 85(3):257-68

Skinner HB, Barrack RL, Cook SD. Age-related decline in proprioception. Clinical Orthopaedics 1984(184):208-11.

Sterling M, Jull G, Vicenzino B, Kenardy J, Darnell R. Development of motor system dysfunction following whiplash injury. Pain 2003; 103(1-2):65-73.

Szeto GP, Straker LM, O'Sullivan PB. A comparison of symptomatic and asymptomatic office workers performing monotonous keyboard work-1: neck and shoulder muscle recruitment patterns. Manual Therapy 2005;10(4):270-80.

Taimela S, Takala EP, Asklof T, Seppala K, Parviainen S. Active treatment of chronic neck pain: a prospective randomized intervention. Spine 2000;25(8):1021-7.

Teng CC, Chai H, Lai DM, Wang SF. Cervicocephalic kinesthetic sensibility in young and middle-aged adults with or without a history of mild neck pain. Manual Therapy 2007;12(1):22-8.

Thunberg J, Ljubisavljevic M, Djupsjobacka M, Johansson H. Effects on the fusimotor-muscle spindle system induced by intramuscular injections of hypertonic saline. Experimental Brain Research 2002; 142(3):319-26.

Treleaven J, Jull G, Sterling M. Dizziness and unsteadiness following whiplash injury: characteristic features and relationship with cervical joint position error. Journal of Rehabilitation Medicine 2003; 35(1):36-43.

Treleaven J, Jull G, Lowchoy N. The relationship of cervical joint position error to balance and eye movement disturbances in persistent whiplash. Manual Therapy 2005;11(2):99-106.

Vilensky JA. Neuromuscular system. In: Brandt KD, Doherty M, Lohmander LS, editors. Osteoarthritis. 2nd ed. New York: Oxford University Press; 2003. p. 161-77 [Chapter 7].

Wang SF, Teng CC, Lin KH. Measurement of cervical range of motion pattern during cyclic neck movement by an ultrasoundbased motion system. Manual Therapy 2005;10(1):68-72.

Westgaard RH, Jensen C, Hansen K. Individual and work-related risk factors associated with symptoms of musculoskeletal complaints. International Archives of Occupational and Environmental Health 1993;64(6):405-13. 